\title{
Visión regional y metropolitana en los planes de ordenamiento territorial de los municipios del área de influencia inmediata de Cali'
}

Regional and metropolitan overview of the land use plans of the municipalities in the area of immediate influence of Cali

\author{
Yanny Alejandro Ramírez Gómez ${ }^{2}$ \\ Wilmar Loaiza Cerón ${ }^{3}$ \\ Oscar Buitrago Bermúdez ${ }^{4}$ \\ Pedro Martín Martínez Toro ${ }^{56^{*}}$
}

\begin{abstract}
Resumen
La identificación de los elementos que permiten evidenciar una visión regional y metropolitana de los municipios del área de influencia inmediata de Cali (Jamundi, Candelaria, Palmira y Yumbo ubicados en el sur del Valle del Cauca y Puerto Tejada localizado en el norte del departamento del Cauca), se realizó a partir de cuatro procesos metodológicos: el primero de ellos llamado Lectura Operativa, en el que se analizó la suficiencia y la articulación de los Planes de Ordenamiento Territorial (POT) en la búsqueda de convergencias regionales, intermunicipales o metropolitanas;
\end{abstract}

\footnotetext{
${ }^{1}$ Este articulo es producto de la investigación "Análisis de la visión regionaly metropolitana en los Planes de Ordenamiento Territorial de los municipios del área de influencia metropolitana de Cali" financiado por la Vicerrectoria de Investigaciones de la Universidad del Valle, a través de la convocatoria interna de 2007.

${ }^{2}$ Geógrafo, Universidad del Valle.

${ }^{9}$ Geógrafo, Universidad del Valle.

${ }^{4}$ Magister en Geografia, Convenio UPTC-IGAC. Profesor de la Universidad del Valle.

5Magister en Geografia, Universidad Carlos III de Madrid. Doctorando en geografía urbana, Universidad Autón oma de Madrid. Profesor de la Universidad del Valle.

" Los autores son integrantes del Grupo de Investigación TERRITORIOS. Departamento de Geografia, Universidad del Valle.
} 
el segundo, denominado ensamble cartográfico, con el cual se identificó a partir de los modelos territoriales municipales propuestos en los POT, las perspectivas que plantea cada municipio que permita reconocer una visión regional y metropolitana; tercero, se hizo el estudio de la incorporación de los lineamientos propuestos en la "Carta de Intención de Cooperación Horizontal" en los POT, y por ultimo, la identificación de elementos para la construcción de una visión metropolitana. Los resultados muestran las discontinuidades y fragmentaciones espaciales en los modelos territoriales municipales, lo cual indica una ausencia de visión de conjunto en cada entidad territorial, evidenciando la necesidad de una construcción colectiva de visiones compartidas, soportadas en alguna figura asociativa como las que prevé la Constitución y la Ley colombiana.

Palabras clave: área metropolitana, lectura operativa, modelo de ocupación del territorio, Plan de Ordenamiento Territorial.

\section{Abstract}

The identification of the elements that allow a regional and metropolitan view of the municipalities in the area of immediate influence of Cali (Jamundi, Candelaria, Palmira and Yumbo located in southem Valle del Cauca and Puerto Tejada located in the north of Cauca), was made from four methodology: the first one called Operative Reading, which examined the adequacy and implementation of Land Management Plans (POT) in the search for regional, metropolitan, or intermunicipality convergence, the second, called map assembly, were was identified from the municipal territorial models proposed on the POT, the perspectives that propose each municipality to recognize a regional and metropolitan view; third, the study of the incorporation of the guidelines proposed in the "Letter of Intent for Horizontal Cooperation" in the POT was made, and finally, the identification of elements for the construction of metropolitan view. The results show the spatial discontinuities and fragmentation in territorial municipality models, which indicates a lack of oversight in each territorial entity, highlighting the need for a collective sharing of visions, supported by some associative figure as foreseen in the Constitution and Laws in Colombia.

Key words: metropolitan area, operational reading, model of land use, Land Management Plan 


\section{Introducción}

El crecimiento de los asentamientos y de la población, el cambio de la base económica subregional y local, la concentración de funciones, las interdependencias y complementariedades en oferta y demanda de bienes y servicios, se consolida una tendencia a desconocer los límites entre entidades territoriales municipales y entre lo rural y lo urbano, que desbordan la capacidad de gestión municipal. La transformación de estos espacios genera nuevas dinámicas espaciales, apareciendo redes, vínculos y flujos formales e informales producto de la extensión de la vida urbana, creando un territorio de complejidad cada vez mayor, en el que se presenta un redimensionamiento de las actividades y las relaciones locales.

Como resultado de estas transformaciones las grandes ciudades tienden a extenderse más allá de los límites administrativos y municipales, generando dificultades para su delimitación, planificación y gestión. Producto a un proceso de desarrollo urbano concentrado en lo regional y disperso en lo metropolitano, se conforman regiones polarizadas, que crecen de manera acelerada aprovechando las economías de aglomeración y de escala, basadas en las ventajas comparativas que generan la localización en zonas de concentración de mercados, actividades productivas, servicios y población, originando fenómenos como la conurbación y la interdependencia funcional, derivando en concentraciones urbanas con grandes áreas de influencia. De acuerdo con Utria (1998), la integración metropolitana, ocurre cuando se da una unión entre los centros urbanos y sus respectivas poblaciones, su estructura ambiental, su espacio socioeconómico y ecológico y su dinámica de desarrollo económico, por encima de los límites político-administrativos, las jurisdicciones y las autonomías municipales.

La interacción de estos procesos origina procesos de metropolización, que funcionan la mayoria de las veces de forma centralizada a partir de una ciudad núcleo, que se relaciona con un conjunto de centros urbanos, denominados como ciudades satélite, las cuales, tienden a especializarse de acuerdo a la función que brindan dentro del área de influencia, 
entre las que se pueden encontrar, cindades dormitorio, industriales, comerciales, recreacionales, etcétera, y por las actividades productivas (centro industrial, centro agrícola, etc.)

De este modo, en los centros urbanos se configuran nuevas relaciones espaciales, en los cuales, el crecimiento del nícleo principal genera una urbanización de nuevos espacios al absorberlos o integrarlos, con la instalación de nuevas y diversas actividades que han sido desplazadas de la ciudad núcleo, debido a las ventajas comparativas de la localización en terrenos menos costosos y más amplios que han sido vinculados a la dinámica urbana pero están designados como rurales. Igual ocurre con las ciudades dormitorio, donde la población encuentra viviendas más baratas que las de la metrópoli. Las vías o corredores metropolitanos que conectan los centros urbanos con la ciudad metrópoli juegan un papel fundamental en la configuración de hechos metropolitanos al propiciar su ocupación por una gran diversidad de usos como los recreativos, educativos, residenciales, comercio e industria, generando procesos de conurbación o acercamiento físico progresivo de los centros urbanos, como resultado de una dinámica de crecimiento, formando un continuo urbano.

Otro fenómeno que se presenta con las áreas metropolitanas es la aparición de espacios periurbanos dispersos, que expresan una interfase entre las áreas urbanas concentradas y las áreas rurales; estos espacios constituyen un territorio en permanente trans formación, donde no existe una continuidad de construcciones; se trata de un territorio en proceso de consolidar nuevas centralidades urbanas, con una gran heterogeneidad de usos del suelo, sometido a procesos mercantiles relacionados con la estimulación económica del precio de la tierra, como consecuencia de la incorporación real o potencial suelos rurales a urbanos.

En Colombia el proceso de metropolización no es desconocido, $\mathrm{y}$ el Estado en varias oportunidades ha querido intervenirlo, ordenarlo y desarrollarlo. El más reciente intento lo constituye la Ley 128 de 1994 , la cual define que las Areas Metropolitanas son entidades administrativas formadas por un conjunto de dos o más municipios integrados alrededor de un municipio núcleo o metrópoli, vinculados entre sí por estrechas 
relaciones de orden fisico, económico y social. Estas áreas se caracterizan por las relaciones de interdependencia entre una ciudad central en la que se localizan ciertas funciones dominantes y una serie de núcleos generalmente más pequefios (menor número de habitantes) y con un menor grado de especialización funcional.

De acuerdo con dicha Ley, los objetivos primordiales de establecer las Areas Metropolitanas son: 1) coordinar y concertar el desarrollo armónico del territorio puesto bajo su jurisdicción, como un solo ente territorial, que trascienda los límites municipales y supere las formas de planificación aislada; 2) organizar y racionalizar la prestación de los servicios públicos a cargo de los municipios que la integran y, 3) ejecutar obras de interés metropolitano que permitan la interconexión y la disposición de nuevos equipamientos de carácter regional. No obstante, el proceso de metropolización en Colombia es concebido como un fenómeno que produce la ruptura de la escala urbana original, el deterioro acelerado de los ecosistemas locales y la reciproca perturbación sanitaria, ambiental y funcional. Cuando el proceso de metropolización no está atendido normativamente se expresa en conflictos de dependencia asimétrica, desarticulación en las politicas públicas y deslealtad intermunicipal en materia de usos del suelo y el control de actividades productivas; aspectos negativos que podrían subsanarse si se avanza hacia una organización supramunicipal, como lo prevéla Constitución y la Ley, que haga viable el manejo unitario, integrado y concertado de la planificación del desarrollo y la prestación de la infraestructura y los servicios básicos.

El proceso de metropolización requiere una planeación y administración integral del territorio y una eficiente coordinación intergubernamental e intersectorial, que demanda una estructura política cuya jerarquía comprenda a las diferentes unidades politico-administrativas involucradas. Lamentablemente la percepción negativa acerca de los alcances reales la norma sobre áreas metropolitanas, soportada en el pretexto de la defensa de la autonomía municipal por parte de las administraciones municipales, ha imposibilitado su adecuada planificación y tratamiento institucional y legal. 
En consecuencia, el desconocimiento politico del fenómeno de metropolización permite que el proceso de crecimiento y conurbación de los grandes centros urbanos colombianos progrese adversamente. Así, Caliy otras capitales importantes del pais pronto se encontraron afectadas por un proceso irreversible de crecimiento desordenado, periférico, de asentamientos marginales y de saturación de la capacidad para prestar los servicios básicos a la población, constituyendo un complejo y enfermo tejido metropolitano que depreda los sistemas ambientales estructurantes, generando un caos administrativo intermunicipal y la pérdida irreversible de potencialidades de dichos centros.

A pesar de lo anterior, las administraciones municipales siguen planteando como principal inconveniente la pérdida de la autonomía local y de un porcentaje del impuesto predial en los municipios, que sería utilizado en la burocracia y ejecución de proyectos metropolitanos, sin tener en cuenta los beneficios de su constitución y las desventajas de una metropolización no planificada.

Otro instrumento normativo que exige desde la planificación municipal considerar hechos intermunicipales, metropolitanos y regionales es la Ley 388 de 1997 y sus decretos reglamentarios, que proponen un ordenamiento del territorio municipal, teniendo en cuenta las acciones político-administrativas y de planificación fisica concertada y coherente, en donde se involucren escalas superiores de planificación como determinantes para el ordenamiento municipal. Los hechos estructurantes intermunicipales, metropolitanos y regionales, deberán plasmarse en la formulación del modelo de ocupación territorial municipal, especificamente en el componente general del Plan de Ordenamiento Territorial, ya que en este se definen las políticas, objetivos y estrategias que consideran las relaciones intermunicipales, metropolitanas y regionales, pretendiendo cohesionar espacial y funcionalmente los modelos territoriales municipales. Es a partir de esta exigencia legal que el presente trabajo sustenta su desarrollo metodológico. 


\section{Proceso metodológico para la identificación de una visión metropolitana de los municipios del área de influencia metropolitana inmediata de Cali}

Esta metodología apunta a identificar y caracterizar los elementos de los Planes de Ordenamiento Territorial de los municipios de Cali, Yumbo, Palmira, Candelaria, Puerto Tejada y Jamundi, que permitan reconocer si existe una visión metropolitana o regional; la cual se desarrolló a partir de un proceso metodológico que involucra cuatro fases, la primera, se denomina Lectura Operativa, utilizada en la conformación del Expediente Municipal (instrumento instaurado por la Ley 388 de 1997 para sustentar ajustes y revisiones al POT); la segunda, el ensamble cartográfico de los modelos del territorio proplestos en los POT de los municipios, para determinar características que brindan una visión regional del área; la tercera, 1lamada Análisis de cumplimiento de los Acuerdos subregionales planteados en la "Carta de Intención de Cooperación Horizontal" dentro de los Planes de Ordenamiento Territorial; y por último, la identificación de elementos para la construcción de una visión metropolitana.

\section{Primera fase: lectura operativa}

El proceso de Lectura Operativa, se desarrolla a partir de dos tipos de análisis que se realizan al POT, los cuales permiten identificar los elementos necesarios para su ajuste; por un lado, está el análisis de suficiencia, el cual consiste en identificar dentro del Plan de Ordenamiento Territorial los componentes y contenidos establecidos en la Ley 388 de 1997 y sil Decreto reglamentario 879 de 1998; y por otro lado, se encuentra el análisis de articulación el cual permite identificar si los contenidos del POT se encuentran relacionados de tal forma que exista una concordancia entre ellos.

El Artículo 2 del capitulo I sobre disposiciones generales del Decreto reglamentario 879 de 1998 establece que "el ordenamiento territorial tendrá en consideración las relaciones intermunicipales, metropolitanas y regionales." Por ello, para efectos de esta investigación, se desarrolló el proceso de Lectura Operativa sobre el componente general de los 
POT, ya que éste, debe contar con los objetivos, estrategias y elementos estructurantes a largo plazo, donde se deberían tener en cuenta estos tipos de relaciones.

En la figura 1 se presenta la caracterización de cada uno de los análisis incluidos en la Lectura Operativa, para la identificación de las relaciones de tipo intermunicipales o regionales que permitan tener indicios de una visión metropolitana, el cual consta de tres fases: la primera, toma como insumo la ley $388 / 97$ y su decreto reglamentario879/98 para disefiar la estructura de las matrices; en la segunda, se realiza el diligenciamiento de las matrices con la información contenida en los POT, y en la tercera, se efectúa el análisis de suficiencia y articulación para identificar los elementos de carácter metropolitano, regional o intermunicipal.

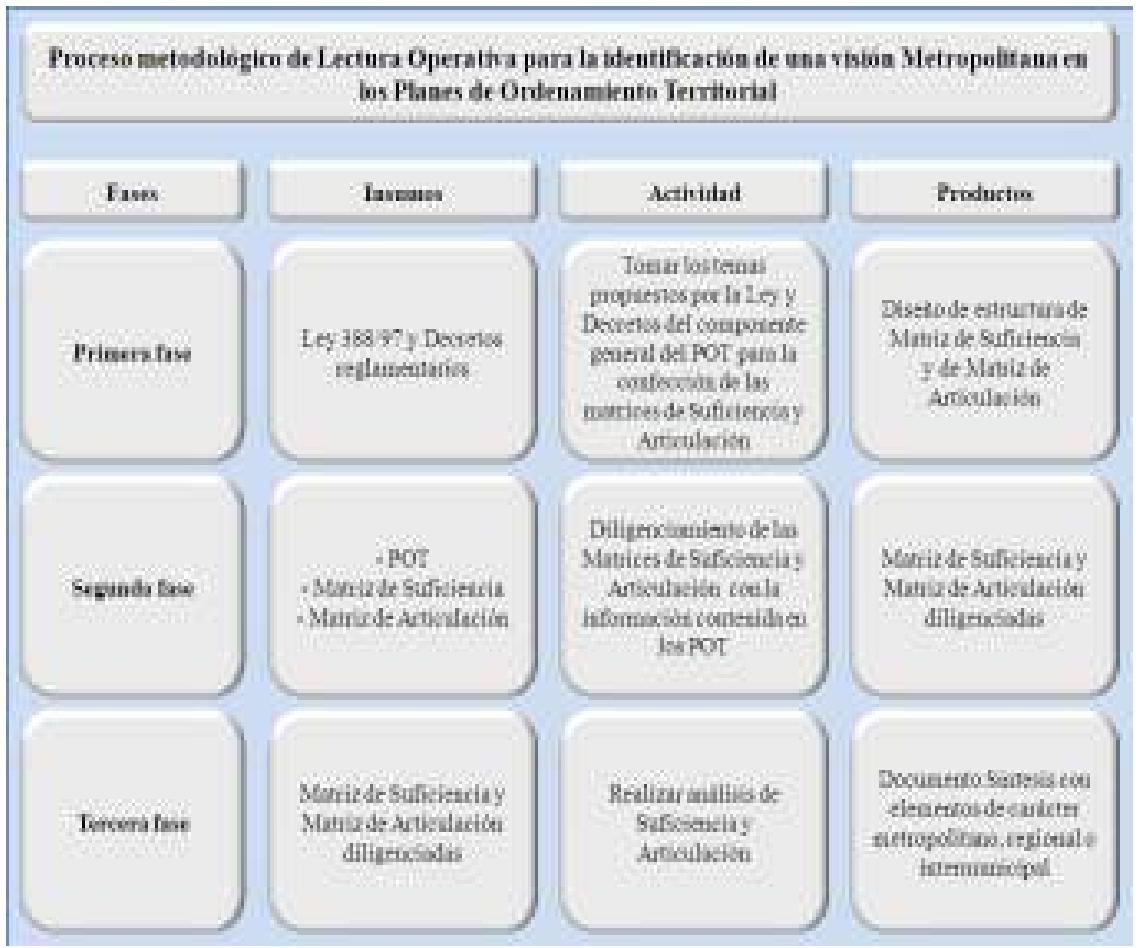

Figura 1. Proceso metodológico de lectura operativa para la identificación de una visión metropolitana en los Planes de Ordenamiento Territorial. Fuente: elaboración propia, 2008. 


\section{Analisis de suficiencia}

$\mathrm{El}$ análisis de suficiencia se realiza para determinar si el POT desarrolla los contenidos específicos que sefiala la Ley 388 de 1997 y el Decreto reglamentario 879 de 1998 , en relación con los procesos regionales y metropolitanos. Para su desarrollo se diligencia una matriz del POT que contiene los temas estructurantes del componente general y se realiza el análisis de suficiencia:

Matriz de suficiencia: está estructurada con base en los contenidos mínimos que debe tener un Plan de Ordenamiento Territorial cuyo diligenciamiento le permitirá a los municipios determinar si éstos cumplen con lo establecido en la Ley 388 y su Decreto reglamentario 879 de 1998 y más específicamente con los contenidos relacionados con elementos intermunicipales, metropolitanos o regionales, que permitan tener indicios de los temas estructurantes de una visión metropolitana. Con laintención de facilitar la construcción de esta matriz, a continuación se describe paso a paso la forma en que está confeccionada y cómo se debe diligenciar, para lo cual es preciso contar con insumos como el documento técnico de soporte y el acuerdo que adopta el Plan de Ordenamiento, de los cuales se obtiene la información que se consigna en las diferentes casillas.

La matriz de suficiencia se estructura a partir de cuatro columnas, la primera llamada contenido segín decreto reglamentario $879 / 98$, donde se debe consignar los temas sefialados para el Componente General del Plan; la segunda nombrada contenido del Plan de Ordenamiento Territorial donde se empieza el diligenciamiento de la matriz, en esta columna se escriben los temas identificados que se relacionan con cada contenido según el Decreto reglamentario 879/98; la tercera columna se llama fuente, en ésta, de acuerdo a los temas, se debe referenciar el número del Artículo o numeral en donde se encuentra contenido, lo que permitirá revisar nuevamente el contenido del documento ya sea para verificar o para ampliar la información; y la cuarta es la columna de observaciones, en ésta se pueden hacer los comentarios relacionados con los contenidos (Ver Cuadro 1). 
Cuadro 1. Estructura de la Matriz de Suficiencia

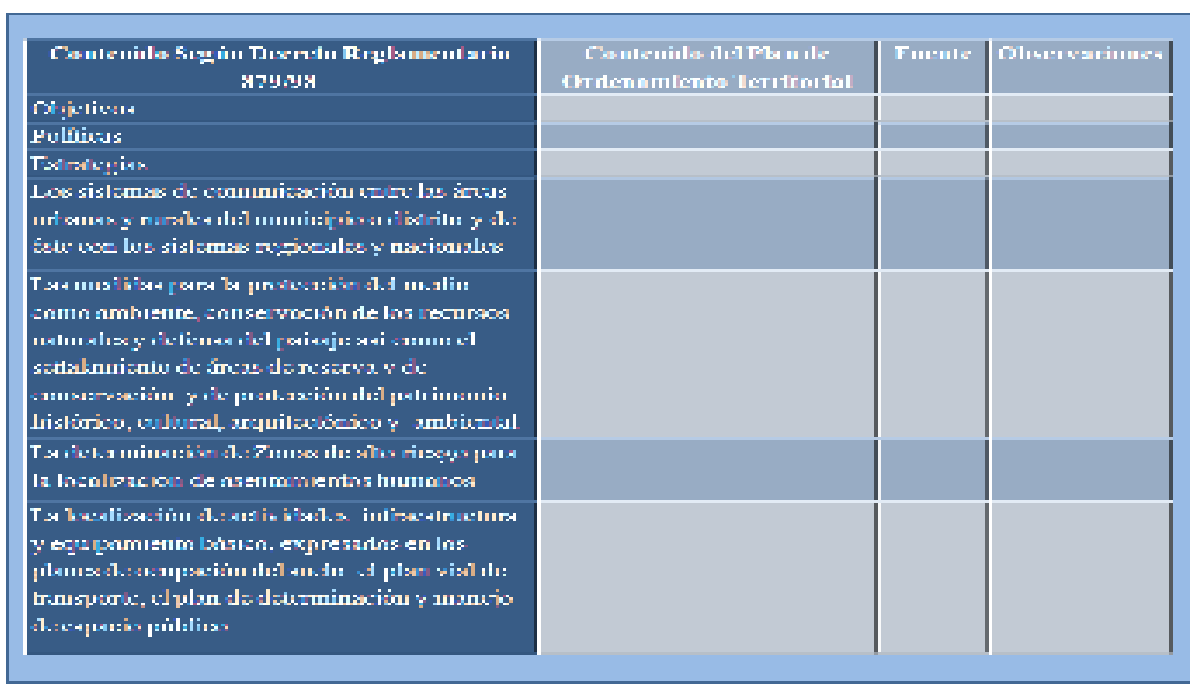

Fuente: elaboración propia, 2008.

Análisis de suficiencia: al tener diligenciada la matriz de suficiencia se deberá proceder a realizar el análisis respectivo, en donde se debe identificar cuáles de los temas propuestos por la Ley 388 de 1997 y su Decreto reglamentario 879 de 1998 se encuentran desarrollados en el plan, lo que permitirá identificar los temas sobre los cuales se promueve la construcción de vínculos regionales en la búsqueda de la constitución de un área metropolitana.

Análisis de Articulación

El análisis de articulación permite establecer si la visión, los objetivos, el modelo de ocupación, las estrategias y los proyectos contenidos en el POT se encuentran articulados entre sí, y si responde a la realidad en la que se enmarca el municipio regionalmente. Para su desarrollo es necesario diligenciar una matriz de articulación y su respectivo análisis:

- Matriz de Anticulación: para realizarla, se debe confeccionar una matriz que permite identificar los vínculos que existen entre la visión, los objetivos y estrategias contenidas en el componente general y su relación con los proyectos que se propone ejecutar de acuerdo a los contenidos afines con elementos intermunicipales, metropolitanos o regionales. 
La articulación que exista entre estos elementos, garantizará la adecuada construcción o incorporación de una visión metropolitana propuesta para el municipio. Este ejercicio es complementario del análisis de suficiencia del POT, en la medida que permite determinar si éste se encuentra bien concebido en tal aspecto, y si hay o no concordancia entre los contenidos.

La matriz de articulación está estructurada a partir de seis columnas, la primera llamada Visión, en la cual se ubica la visión del respectivo plan que se está analizando; la segunda recibe el nombre de Elementos de la Visión, en ésta se sitían aquellos elementos que en la visión hagan referencia a temas regionales o metropolitanos; la tercera nombrada Objetivos, esta columna contiene los objetivos propuestos en el plan, para desarrollar los elementos de la visión; la cuarta llamada Estrategias, la cual contiene las estrategias relacionadas con los objetivos; la quinta es la de los Proyectos en la cual se ubican de acuerdo a la relación con los objetivos o a las estrategias; por íltimo, está la columna del Modelo territorial, en la cual se ubica el modelo propuesto por el POT en téminos regionales o metropolitanos para el municipio. (Ver Cuadro 2)

Cuadro 2. Estructura de la Matriz de Articulación

\begin{tabular}{|c|c|c|c|c|c|}
\hline VIslón & $\begin{array}{c}\text { Elementos de } \\
\text { la Vlsión }\end{array}$ & Objetlvos & Estrateglas & Proyectos & Modeloterritorlal \\
\hline $\begin{array}{c}\text { Visión } \\
\text { municipal que sc } \\
\text { encuentra en el } \\
\text { POT }\end{array}$ & $\begin{array}{l}\text { aspcctos de la } \\
\text { visión } \\
\text { municipal } \\
\text { relacionados } \\
\text { con temas de } \\
\text { csrńcler } \\
\text { regional }\end{array}$ & $\begin{array}{l}\text { Objetivos } \\
\text { relacionados } \\
\text { con los } \\
\text { clcmentos de } \\
\text { la vision }\end{array}$ & \begin{tabular}{|c|} 
Estrategias \\
relacionadas \\
con el objelivo \\
o con cl \\
clcmento de la \\
viniin
\end{tabular} & $\begin{array}{l}\text { proycctos } \\
\text { estratceicos } \\
\text { thel lo()l' 'yut } \\
\text { desarrollen las } \\
\text { estratceias o } \\
\text { less orjelivess }\end{array}$ & $\begin{array}{l}\text { modelo del } \\
\text { territorio propucsto } \\
\text { tebe reflejure a } \\
\text { partir de los } \\
\text { clementos } \\
\text { estruclursiles del } \\
\text { POT }\end{array}$ \\
\hline
\end{tabular}

Fuente: elaboración propia, 2008.

Análisis de articulación: para realizar el análisis se debe tener en clenta los siguientes criterios:

- Todo los elementos de la visión deben tener al menos un objetivo relacionado 
- Que los objetivos tengan estrategias asociadas

- Que las estrategias cuenten con planes, programas, proyectos para su ejecución

- Definir si hay o no concordancia entre los elementos de la matriz

- Definir si los elementos de la matriz están contribuyendo a alcanzar el modelo territorial propuesto en el tema regional y/o metropolitano.

\section{Segunda fase: ensamble cartográfico de los modelos del territorio propuestos en los POT}

E1 modelo del territorio es el "resultado de la interrelación de los diversos factores del medio y la actividad humana, con base en el análisis de la evolución histórica, y teniendo en cuenta, además, los sistemas de relaciones, las infraestructuras, los equipamientos y los servicios administrativos" (Cabildo de Tenerife, s.f.), sobre el cual se establecen una serie de propósitos y proyectos con efectos estructurantes sobre el territorio, previo al establecimiento de unos objetivos y criterios de ordenación. De acuerdo con el parágrafo 1 artículo 12 del capítulo III llamado Planes de Ordenamiento Territorial de la ley 388 de 1997, el modelo de ocupación del territorio "fija de manera general la estrategia de localización y distribución espacial de las actividades, determina las grandes infraestructuras requeridas para soportar estas actividades y establece las características de los sistemas de comunicación vial que garantizarán la fluida interacción entre aquellas actividades espacialmente separadas."

Para el caso del área de influencia directa metropolitana de Cali, este ensamble de visiones debe ser combinado de tal manera que primen y se consoliden las fiertes interrelaciones, dependencias, especializaciones y afecciones que unen a los municipios que conformatían la región, con el objetivo de alcanzar una imagen conjunta del mecanismo de funcionamiento del territorio.

En consecuencia, el Modelo de Ordenación Territorial deberá presentar aquellos elementos de la ordenación que se convierten en piezas claves de la consolidación regional, como son: 
- Los sistemas de comunicación entre las áreas urbanas y rurales del municipio y de este con los sistemas regionales y nacionales.

- Las medidas para la protección del medio ambiente, conservación de los recursos naturales y defensa del paisaje, así como el señalamiento de áreas de reserva y de conservación ambiental.

- La determinación de zonas de alto riesgo para la localización de asentamientos humanos.

- La localización de actividades, infraestructuras y equipamientos básicos, expresados en los planes de ocupación del suelo, el plan vial y de transporte, el plan de vivienda social, los planes maestros de servicios públicos, el plan de determinación y manejo del espacio público.

- La clasificación del territorio en suelo urbano, nural y de expansión urbana, con la correspondiente determinación del perímetro urbano que no podrá ser mayor que el perímetro de servicios públicos.

Con el objetivo de reconocer espacialmente los puntos en común y las discontinuidades que se presentan en los límites municipales, se realizó el ensamble cartográfico de "Los modelos territoriales propuestos" y la "Calificación de usos del suelo propuestos" en los POT de los municipios, para identificar los elementos que restringen o propician la interconexión regional o pueden generar conflictos de usos del suelo; además, los resultados de este procedimiento ayudaron a determinar las características que brinda cada municipio para construir una visión regional del área, como son la planificación de nuevas vías interregionales e intermunicipales, las zonas de protección compartidas, la construcción de infraestructuras y megaproyectos de escala regional, la propuesta de zonas para la disposición final de residıos sólidos para la subregión y demás elementos que permitan la interconexión, complementariedad y estructuración del área metropolitana de Cali.

En la Figura 2 se observa la metodología propuesta para el ensamble cartográfico de los modelos del territorio propuestos en los POT municipales, la cual consta de tres fases: en la primera se realizó el proceso de georeferenciación y digitalización de la cartografia necesaria para construcción de los modelos; en la segunda fase se homologaron las categorías de uso propuestas por cada POT municipal y por último, 
al obtener los ensambles de los modelos del territorio se identificaron los elementos estructurantes regionales de cada modelo de ocupación territorial.

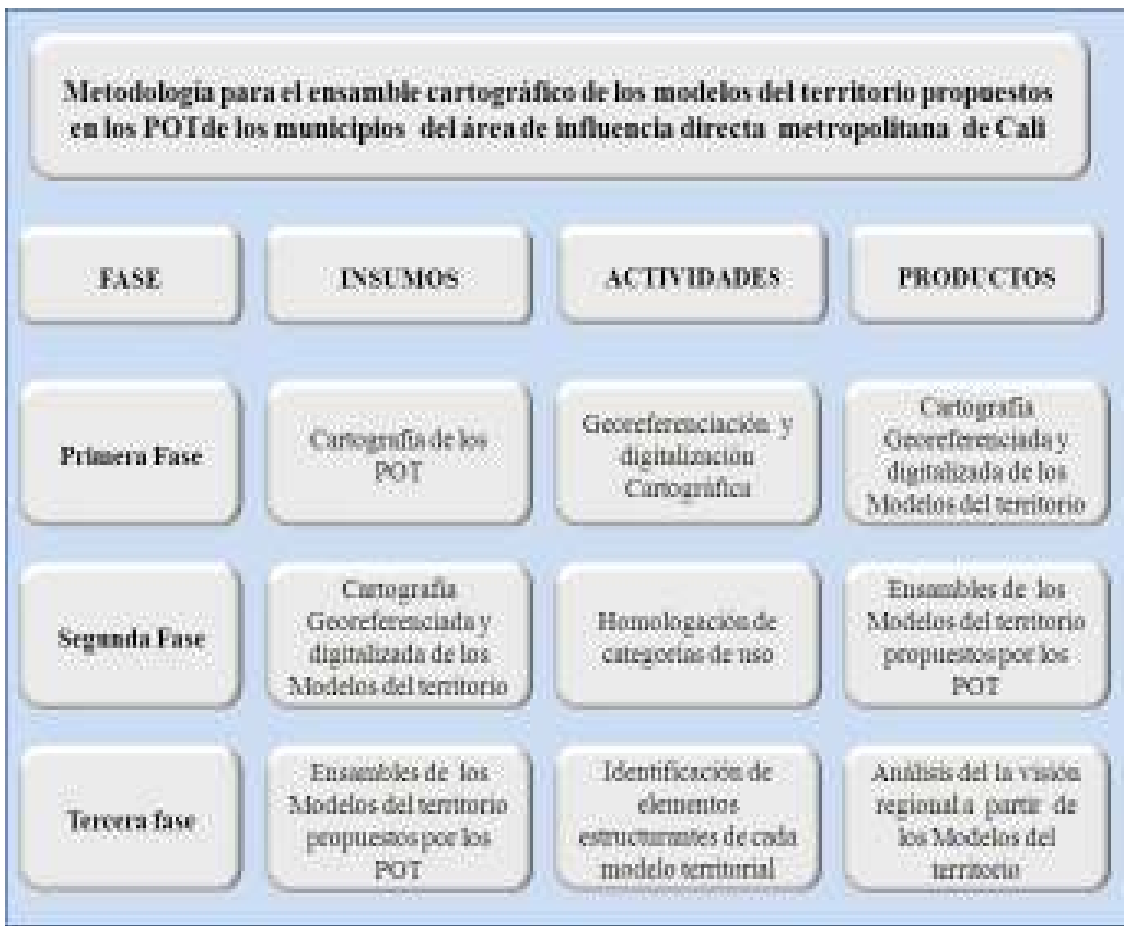

Figura2. Metodología para el ensamble cartográfico de los modelos del territorio propuesto.

Fuente: elaboración propia, 2008.

Para generar este ensamble, se desarrollaron las siguientes fases: la primera, consiste en realizar la Georeferenciación de los mapas que presentan los POT, puesto que casi siempre aparecen como imágenes jpeg, mapa de bits, etc., por medio del software ArcGis 9.0, es decir, se define la localización correcta sobre la superficie de la tierra en un sistema de coordenadas determinado de las imágenes de cada modelo y calificación de uso propuesto. En otras palabras, la Georeferenciación es la relación que se establece entre las imágenes de cada modelo y su ubicación en el mundo real. 
Posteriormente, con las imágenes georeferenciadas se realiza su digitalización, para generar las capas necesarias de cada modelo del territorio propuesto, 10 cual, proporciona el área de influencia metropolitana de Cali con los modelos del territorio de cada uno de sus municipios.

Sin embargo, debido a la cantidad y heterogeneidad de calificativos determinados para cada una de las categotías de usos del suelo de los Modelos del territorio planteados por los POT municipales, fie necesario plantear una homologación de estas categorías y construir el modelo a partir de varios mapas, bajo los principios de la Ley 388/97 y su Decreto reglamentario 879/98, para crear una leyenda general de los modelos del territorio y la calificación de los usos del suelo del área metropolitana.

Teniendo en cuenta el Capítulo III del Decreto 879 de 1998 relacionado con los componentes y contenidos de los Planes de Ordenamiento Territorial, en el cual se explican los contenidos que estructuran el componente general, se establecieron 10 Categorías para los modelos del Territorio y 27 para la Calificación de usos del suelo, las cuales agrupan los diferentes calificativos dados por cada Municipio a sus respectivas propuestas; es importante resaltar que no todas las categorías aparecen en cada propuesta, puesto que los objetivos y la visión de cada POT apuntan a cubrir las necesidades y realidades de su territorio.

Finalmente con la cartografia digitalizaday las categorias homologadas se obtiene el ensamble cartográfico de los modelos del territorio y de calificación de usos del suelo propuestos por los Planes de Ordenamiento Territorial de los municipios del área de influencia directa metropolitana de Cali.

En las figuras 3 y 4 se presentan los resultados obtenidos del ensamble cartográfico de los modelos del territorio y la calificación de usos del suelo propuestos por los municipios.

\section{Tercera fase: análisis de cumplimiento de los acuerdos subregionales}

La "Carta de Intenciones para la Cooperación Horizontal Municipal en el sur del Valle, Zona Pacifica y norte del Canca" fue firmada en 1998 
por los alcaldes de los municipios de Buenaventura, Candelaria, Dagua, Jamundi, La Cumbre, Palmira, Puerto Tejada, Santander de Quilichao, Santiago de Cali y Yumbo, en la cual "reconocen que conforman una estructura territorial interdependiente y que por su naturaleza $y$ complejidad requieren del desarrollo conjunto, coordinado y solidario de acciones que conduzcan al desarrollo equilibrado de la subregión" (Comité Técnico de Planificación del sur del Valle, Zona Pacifica y Norte del Cauca, 1998, citado por: Martínez, 2005, 71).

En esta carta se establecieron y concertaron los acuerdos subregionales que debian ser incluidos dentro de los Planes de Ordenamiento Territorial de cada municipio, para resolver problemáticas que no podían solucionarse de manera aislada y, acordar un mínimo de requerimientos para temas como usos del suelo limítrofes o disposición de nuevos equipamientos y grandes proyectos en el área, con el fin de disminuir conflictos en tal sentido. Sin embargo es importante aclarar que esta carta es de carácter indicativo mas no vinculante, es decir que los municipios no están obligados a cumplir con lo plasmado en este documento. 


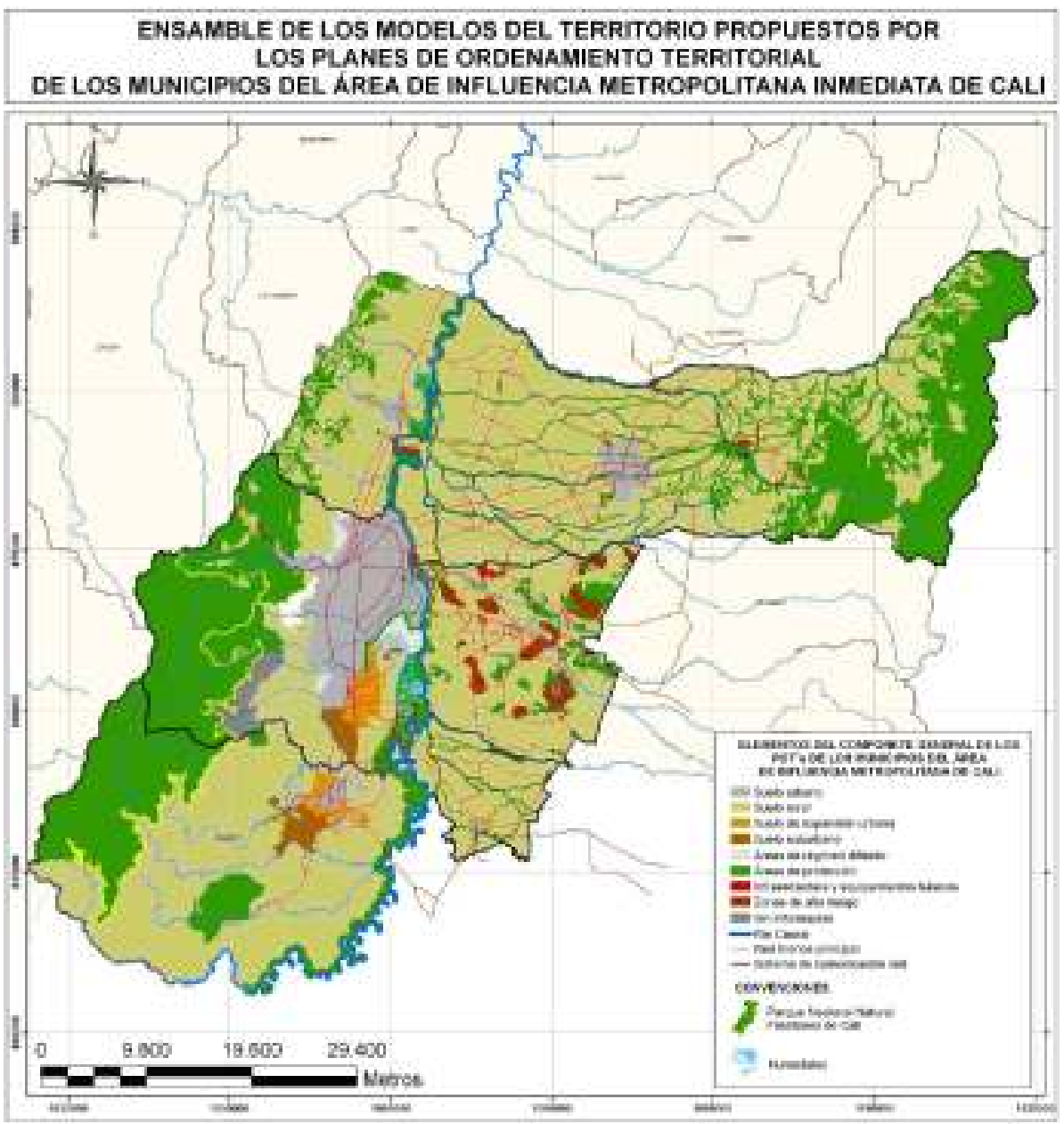

Figura 3.ensamble de los modelos del territorio propuestos por los Planes de Ordenamiento Territorial de los municipios del área de influencia metropolitana de Cali. Fuente: elaboración propia, 2008. 


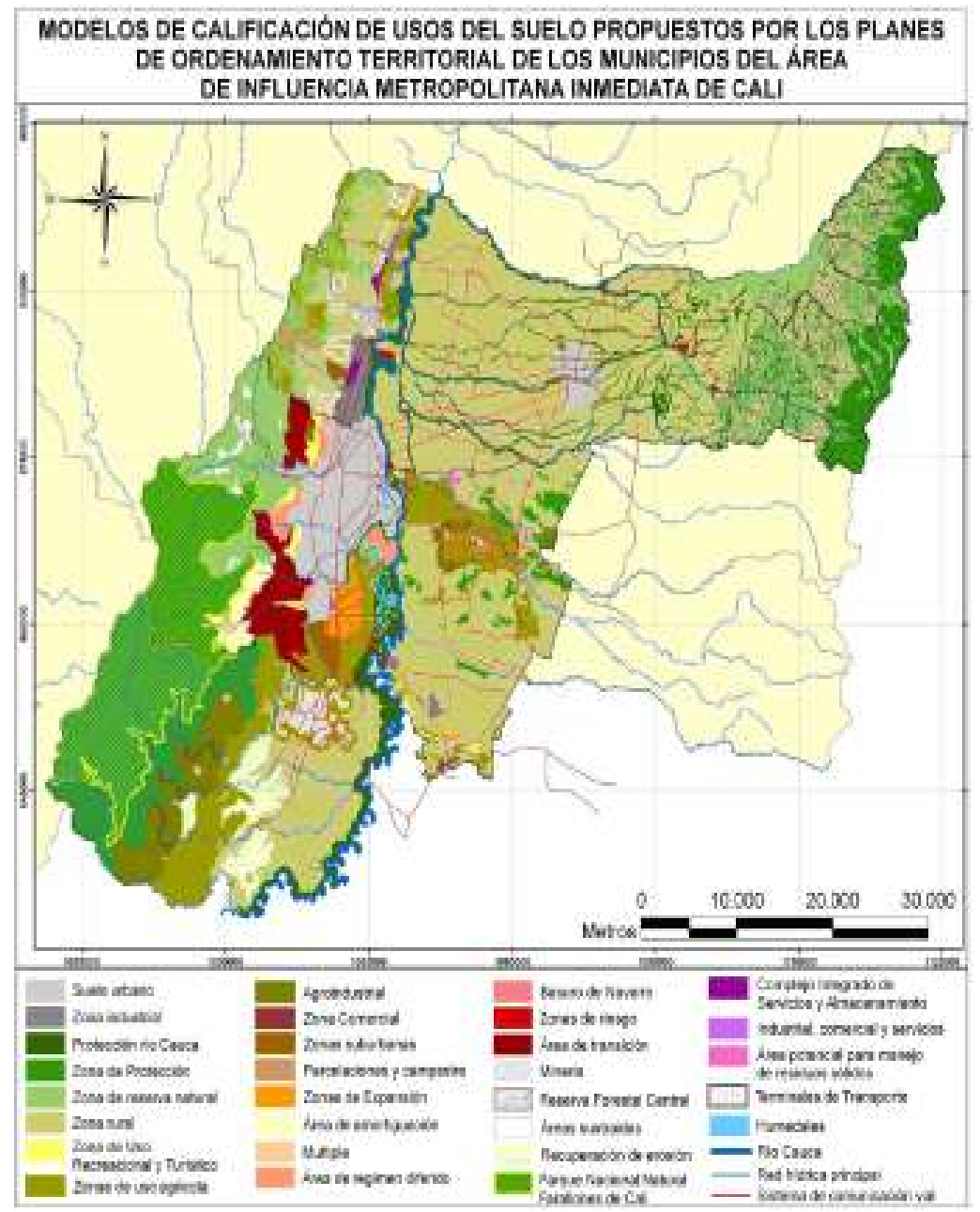

Figura 4. Ensamble de los modelos de calificación de usos del suelo propuestos por los Planes de Ordenamiento Territorial de los municipios del área de influencia metropolitana de Cali. Fuente: elaboración propia, 2008.

E1 análisis de aceptación de la "Carta de Intención de Cooperación Horizontal" busca identificar y describir los elementos asumidos por los municipios del primer anillo metropolitano de Cali dentro de los Planes de Ordenamiento Territorial en el marco de los acuerdos y compromisos establecidos en ésta. 
En la figura 5 se muestra el proceso metodológico que se siguió para el estudio de aceptación de los lineamientos propuestos en la carta, el cual, está conformado por tres fases: en la primera, se realiza el disefio de la matriz de cumplimiento de los acuerdos subregionales teniendo en cuenta la lectura operativa y el acta $\mathrm{N}^{\circ} 018$ "Carta de Intención de Cooperación Horizontal"; en la segunda fase se realizó el diligenciamiento de la matriz y posteriormente con los resultados obtenidos se logró identificar como ha sido asumido el proceso de metropolización.

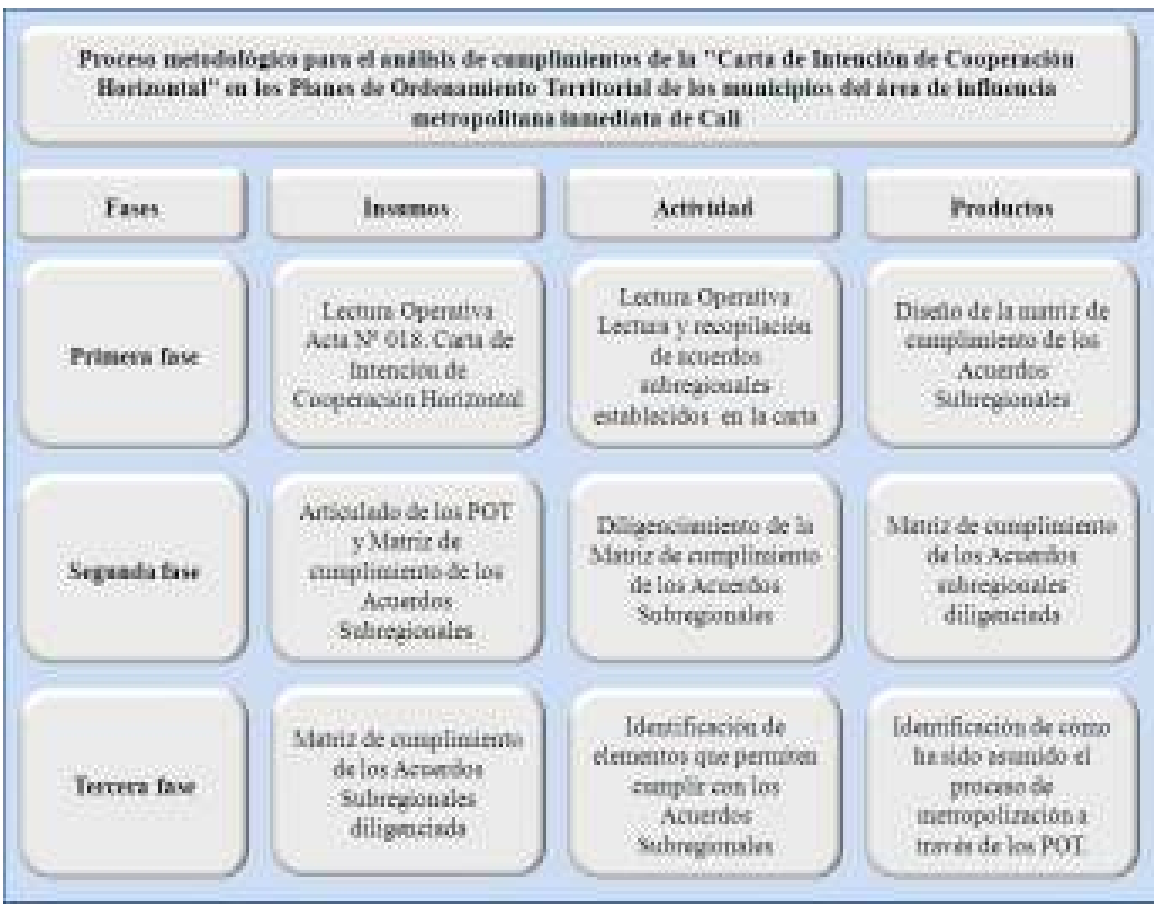

Figura 5. Proceso metodológico para el análisis de aceptación de compromisos de la "Carta de Cooperación Horizontal". Fuente: elaboración propia, 2008.

\section{Cuarta fase: identificación de elementos de una visión regional o} metropolitana a partir de los planes de ordenamiento territorial

La construcción de un área metropolitana como entidad administrativa implica la consolidación de una visión que permita convertir el territorio en una unidad planificada que cumpla con las condiciones necesarias para 
un desarrollo territorial basado en la equidad, sostenibilidad ambiental, competitividad y la gobernabilidad; estableciendo mecanismos que coadyuven a concertar y alcanzar acuerdos con los municipios que conforman el primer anillo metropolitano.

Los municipios que hacen parte del área de influencia directa metropolitana tienen en sus Planes de Ordenamiento Territorial ciertos elementos que permiten identificar los procesos de metropolización que son comunes para la región, pero que son abordados desde la individualidad de los municipios por el temor de perder su autonomía al vincularse como elemento estructural del área metropolitana. Para mostrar cómo se abordan desde cada municipio los temas regionales se presentan los elementos que de acuerdo con el Decreto reglamentario 879/98 deben contener los POT en el componente general, teniendo en cuenta los resultados obtenidos en cada una de las fases anteriores:

\section{Objetivos de los POT municipales referentes a la región}

En el contexto del área de influencia directa metropolitana de Cali, los objetivos de los POT municipales deben propiciar la construcción de un modelo regional sostenible, que convierta a la región en una unidad de planeamiento reconocible y establezca los mecanismos que permitan concertar y alcanzar acuerdos con los municipios que la constituyen, para la promoción de un modelo territorial sostenible que propenda por el aprovechamiento y manejo adecuado de los recursos, la equidad, la organización y el fortalecimiento del territorio. De acuerdo con esto, 10 s objetivos de cada municipio que evidencian la visión subregional son:

E1 POT de Cali propone la articulación y conectividad de la ciudad región mediante sistemas avanzados de comunicación con su entorno a partir de corredores interregionales que permitan el intercambio de bienes y servicios en el ámbito regional e internacional; por su parte el POT de Palmira busca integrar el sistema de áreas protegidas a nivel nacional y consolidar la protección del río Cauca para elevar la calidad ambiental del municipio y la región, además articular la malla vial con la región y aprovechar las ventajas comparativas de sul localización. 
Los objetivos regionales o metropolitanos primordiales del PBOT de Yumbo son promover el ordenamiento y articulación regional de los municipios que hacen parte del área metropolitana de Cali para determinar su vocación y especialización, consolidando un modelo de desarrollo urbano regional cuyos ejes estructurantes sean la malla vial y el río Cauca, en la búsqueda de la protección y conservación de los recursos naturales y la sostenibilidad ambiental para generaciones futuras, esto, basado en las ventajas comparativas que ofrece el territorio para el logro de una mayor productividad y competitividad frente a nuevos retos de la economía regional y nacional.

Por otro lado, el PBOT de Jamundi plantea el desarrollo equilibrado de la región fomentando el crecimiento de la población y su área de influencia en arm onía con el Medio ambiente, para fomentar su progreso y disminuir las migraciones de poblaciones vecinas, las cuales incrementan los problemas socioeconómicos del municipio, además, plantea el fortalecimiento empresarial y técnico-científico de la región, mediante la diversificación industrial y la consolidación de la infraestructura básica para el desarrollo de la ciencia y la tecnología; el fin del PBOT de Puerto Tejada es posibilitar el manejo adecuado de los recursos hídricos en coordinación con los municipios y departamentos vecinos, al tiempo que se involucre al municipio en una visión regional, basada en las necesidades prioritarias de la gestión ambiental; por último, el PBOT de Candelaria busca articular el municipio al desarrollo regional, concertando convenios intermunicipales para infraestructuras de carácter regional y nacional y de temas relacionados con la gestión integrada de los recursos hídricos.

\section{Sistemas de comunicación entre las áreas urbanas y rurales del municipio y de éste con los sistemas regionales y nacionales}

De acuerdo con la lectura operativa y los modelos del territorio de los POT estudiados, se contempla un sistema de comunicación que permita el funcionamiento espacial adecuado como elemento vital y decisivo en la consolidación del área metropolitana, estableciendo un sistema vial jerárquico, de vías interregionales, principales y urbanas, a demás 
de incorporación de la vía férrea como estrategia para la interconexión regional.

\section{Medidas para la protección del medio ambiente, conservación de} los recursos naturales y defensa del paisaje.

Los POT municipales respecto a este tema, tienen como punto en común lo establecido en la "carta de intención de cooperación horizontal", en la que reconocen el lugar preponderante que ocupa el río Cauca en la subregión, promoviendo su manejo integrado, preservación ambiental, descontaminación y recuperación, a demás establecen los tipos de usos que son restringidos, compatibles y prohibidos con el fin de garantizar y mejorar la calidad ambiental del mismo. Sin embargo, no se logra integrar una estructura ecológica, puesto que la franja de protección de río no es continúa, como ocurre en los casos de Puerto Tejada y Candelaria.

En los municipios que se comparte la jurisdicción del Parque Nacional Natural los Farallones de Cali (Jamundi y Cali), como se observa en la figura 6 , se proponen procesos participativos de ordenamiento ambiental para la consolidación, caracterización y reglamentación de la zona amortiguadora, que posibiliten la conservación de la oferta ambiental del parque. 


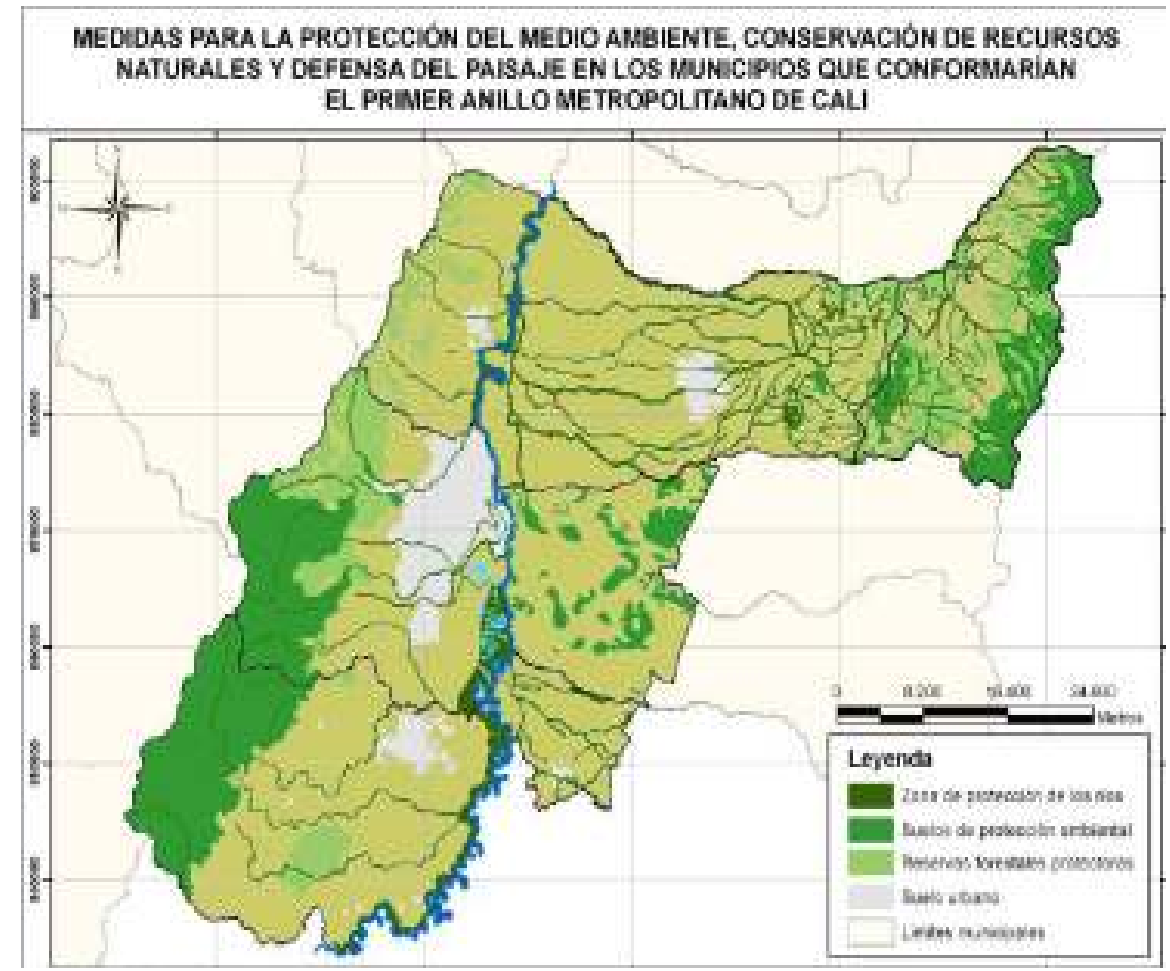

Figura 6. Medidas para la protección del medio ambiente, conservación de recursos naturales y defensa del paisaje en los municipios que conformarian el primer anillo metropolitano de Cali. Fuente: elaboración propia, 2008

\section{Determinación de zonas de alto riesgo para la localización de asentamientos humanos}

De acuerdo con el análisis realizado, los municipios del área de influencia metropolitana de Cali localizados en la margen izquierda del tío Cauca a demás del municipio de Palmira, han determinado las zonas de amenaza y al to riesgo por la inundación del río. El POT de Cali determina una franja de terreno del río Cauca como área forestal protectora, para la mitigación de amenaza por posibles crecientes. En el caso de Yumbo se propone zonas de amenaza por la inundación tradicional del tío Cauca; por su parte el POT de Palmira plantea la realización de estudios con el fin de identificar las acciones necesarias para la reubicación, mitigación 
de riesgos y construcción de obras de saneamiento ambiental del río Cauca para solucionar los conflictos generados por la localización en el área forestal protectora de los asentamientos de Piles, Barrio Pereira, los Industriales de Juanchito y Cauca seco.

Por otro lado, Candelaria define las áreas de extrema vilnerabilidad de acuíferos identificadas como zona de protección, que excluyen otros tipos de actividades. En cuanto a los riesgos por fenómenos de remoción en masa, en Cali y Palmira son determinados en los modelos del territorio.

Aunque algunos municipio determinan las zonas de alto tiesgo para la localización de asentamientos humanos, ésta se muestra de manera aislada, sin tener en cuenta implicaciones de carácter regional, que podrían tener mayor importancia para la gestión del riesgo y la protección de la población del área metropolitana.

\section{Localización de actividades, infraestructura y equipamiento básico.}

Aunque los municipios plantean la localización de infraestructura y equipamientos básicos, se identificaron algunos que no son pertinentes con la escala de trabajo del proyecto, por lo cual no se presentan en la cartografia sobre los modelos del territorio. Los principales propósitos del POT de Cali referentes a este tema son la consolidación de los espacios públicos como son el centro tradicional que cubrelas actividades económicas para los habitantes, las terminales de transporte, los centros de salud, de educación y culturales, los escenarios deportivos de alta competencia, tales como velódromos y piscinas. Con el fin de promover la educación ambiental y participación pasiva o activa, reconoce los parques de escala urbano regional (eco parque Bataclán y el parque de la Salud) y los futuros parques denominados las Tres cruces, Cristo rey, los Cristales y la Bandera.

El municipio de Jamundi plantea en el corto plazo definir la disposición final de residuos sólidos, bien sea de nivel local, o regional en asocio con otros municipios, de manera que se permita la habilitación definitiva de un sitio para dicha actividad. Además de la definición de polígonos mineros; 
en el caso de Yumbo se propone la ampliación del sistema de energía hasta alcanzar el cien por ciento del casco urbano y la zona industrial y la implementación de un proyecto de tipo sanitario-ambiental que pretende prestar el servicio para la disposición final de basuras al municipio de Yumbo y a los municipios circunvecinos que asi lo requieran.

De acuerdo con el POT de Candelaria el espacio público constituye una política estructurante en éste, como medida para la generación de espacios de encuentro, de intercambio y de comunicación entre los poblados del municipio y de estos con sus municipios más cercanos. Además de la determinación del área potencial para el manejo de residuos sólidos y la propuesta para la construcción de una estación de transferencia de residuos sólidos y las posibles áreas para explotación minera. Puerto Tejada plantea una franja de doscientos metros para la consolidación del basurero municipal o regional y la escombrera municipal, también reconoce la Zona Minera de Comunidades Negras al noroccidente del municipio. E1 Plan de Ordenamiento Territorial del municipio de Palmira propone el plan maestro de residuos sólidos en el que se especifica el sitio de disposición final de residuos sólidos asociado a las expectativas regionales.

\section{Conclusiones}

Respecto a los resultados del trabajo realizado para la identificación de elementos que brindan una visión regional y metropolitana de los municipios del área de influencia de Cali, se pueden destacar dos situaciones de gran importancia:

La primera, que los resultados obtenidos muestran un marcado interés por promover la recuperación, protección y conservación de la función ecológica, social y económica del río Cauca y sus afluentes, basados en la concertación y la construcción de convenios intermunicipales para la vigilancia permanente de los tíos con el fin de disminuir la carga contaminante de los vertimientos industriales del área; aunque el PBOT de Puerto Tejada no deja por escrito su compromiso, cartográficamente plantea un modelo en el que se determinan las áreas forestales protectoras 
de los tíos que están dentro de su jurisdicción y determina una franja interrumpida de protección del río Cauca. Sin embargo, los demás compromisos adquiridos en el eje Ambiental quedan descubiertos, el único POT que deja por escrito la importancia de establecer las áreas de protección y/o conservación de los elementos constitutivos del soporte ambiental de la región, es Yumbo, no obstante, el Artículo en el que lo registra, es una copia directa del párrafo que habla del tema en la Carta, así que, este no garantiza el cumplimiento del mismo. Es importante reconocer que, aunque no se mencionan las áreas de protección en los articulados de los POT, espacialmente los municipios si determinan las áreas de protección y conservación ambiental de los Parques dentro de su jurisdicción, como son el Parque Nacional Natural Farallones de Cali en Jamundí y Cali, el Parque Nacional Natural las Hermosas en Palmira, las zonas de reserva forestal protectora del Chontaduro y Guachinte en Jamundi, la Zona de reserva forestal protectora de la CVC, y las áreas de extrema vulnerabilidad de acuíferos en Candelaria.

En segundo lugar, que los municipios de Cali, Candelaria, Jamundi, Palmira, Yumbo y Puerto Tejada participan de una dinámica de aglomeración urbana, la cual, no se puede entender ni intervenir sin tomar en consideración sus entomos inmediatos. Por ello, es pertinente considerar la conformación de una figura mancomunada para la administración de problemas y potencialidades comunes, que ponga fin a los procesos de degradación ambiental, los problemas de integración física, económica y social, y haga frente a las desigualdades de desarrollo, producto de la deficiente planificación del territorio desde una perspectiva regional. Compromiso que compete a todos los actores de desarrollo y exige la cooperación, coherencia y continuidad en las intervenciones dentro del área. Además, se hace necesario la construcción colectiva de visiones compartidas, que permitan la articulación del trabajo de las instituciones del Estado entre sí y con las organizaciones de la sociedad, así como la aplicación de estrategias de desarrollo territorial. 


\section{Bibliografía}

Alcaldia de Candelaria. 2005. Acnerdo 015 de 2005. Plan Básico de Ordenamiento Territorial. Candelaria: Alcaldia de Candelaria.

Alcaldia de Palmira. 2001. Acuerdo 109 de 2001. Plan de Ordenamienro Territorial. Palmira: Alcaldia de Palmira.

Alcaldia de Santiago de Cali y Departamento Administrativo de Planeación Municipal. 2000. Plan de Ordenamiento Territorial. Cali: Alcaldia de Santiago de Cali. $231 \mathrm{p}$.

Alcaldia de Yumbo. 2001. Acuerdo No 0028 de 2001. Plan Básico de Ordenamiento Territorial. Yumbo: Alcaldia de Yumbo.13p

Area metropolitana del Valle de Aburrá. 2007. Plan integral de desarrollo metropolitano. METR OPOLI 2008-2020. Hacia la integración regional sosten ible. Medellin : oficina asesora de comunicaciones del área metropolitana del Valle de Aburra. $280 \mathrm{p}$.

Cabildo de Tenerife. Avance del plan territorial parcial de ordenación de la comarca del área metropolitana. España: Cabildo de Tenerife, s.f. p. $198-202$

Congreso de la República de Colombia. 1997. Ley 388 de 1997. Por la cual se modifican la Ley 9 de 1989 , y la Ley 2 de 1991 y se dictan otras disposiciones. Tbagué: el antor. $123 \mathrm{p}$.

Instituto Geográfico Agustin Codazzi. 1988. Caracterización del proceso de urbanización en Colombia. En: Análisis geográfico. No ${ }^{\circ} 15$ p. 134-254

Martinez, Pedro. 2005. La integración subregional y la caracterización funcional, morfólógica del fenómeno de metropolización en el área de influencia metropolitana de Cali. En: Actas Latinoamericanas de Varsovia. Tomo 28 p. 67-91. ISSN 0866-9953

Ministerio de Desarrollo Económico. 1998. Decreto 879 de 1998. Por el cual se reglamentan las disposiciones referentes al orden amiento territorial municipal y distrital y los planes de ordenamiento territorial. Bogotá. 15p.

Precedo, Andrés. 1996. Cindad y desarrollo urbano. Madrid: Sintesis. p. 227-257. ISBN 84$7738-386-3$

Utria, Rubén. 1998. Metropolización de la sabana de Bogotá. En: disertación en los martes del planetario. "Metropolización, Planeación y Ordenamiento Territorial". (1998, Bogotáy. Sociedad Geográfica de Colombia. 25p.

Recibido: marzo 2008

Aceptado: agosto 20 de 2008 